Interactive comment on "Physical-biogeochemical regional ocean model uncertainties stemming from stochastic parameterizations and potential impact on data assimilation" by Vassilios D.

\title{
Vervatis et al.
}

Vassilios D. Vervatis et al.

vervatis@oc.phys.uoa.gr

Received and published: 16 June 2019

The response was uploaded in the form of a supplement pdf file.

Please also note the supplement to this comment:

https://www.geosci-model-dev-discuss.net/gmd-2019-31/gmd-2019-31-AC1- 
2019.

GMDD

Interactive

comment 